\title{
GIANT CELL GRANULOMA ASSOCIATED WITH LESIONS RESEMBLING POLYARTERITIS NODOSA
}

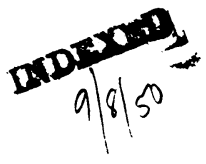

\author{
BY \\ G. H. HOWELLS AND I. FRIEDMANN \\ From the Institute of Laryngology and Otology, London
}

(RECEIVED FOR PUBLICATION MARCH, 1950)

The association of peculiar giant-cellular granulomatous lesions of the upper respiratory tract and the lungs or other organs with necrotizing vascular lesions resembling polyarteritis nodosa has been seldom reported. Klinger (1931) described one case ; Rössle (1936) one case ; Wegener (1939) three cases ; Neumann (1940) four cases ; Banowitch, Polayes, and Charet (1942) one case ; Lindsay, Aggeler, and Lucia (1944) one case ; Weinberg (1946) two cases ; and Smith (1948) one case. The aetiology of the cases reported was obscure, but such lesions have been associated with various factors, for example, foreign serum, foreign serum and sulphonamide therapy, or sulphonamide therapy, especially sulphathiazole alone (Lederer and Rosenblatt, 1942 ; Rich, 1942a, 1942b ; Rich and Gregory, 1943 ; Lichtenstein and Fox, 1946 ; Duff, More, and McMillan, 1946 ; van Rijssel and Meyler, 1949 ; Olesen and Myschetzky, 1949 ; and others). Rössle (1936) considered a rheumatic aetiology and Weinberg (1946) pointed out that similar granulomatous lesions of unknown aetiology, but not associated with polyarteritis nodosa, have been described as far back as 1906.

The salient features, according to Weinberg, were a history of long-standing infection of the upper respiratory tract with the development of ulceration of the nose, mouth, and trachea and with the final development of polyarteritis nodosa. Rössle's case showed involvement of the paranasal sinuses and the ear. Wegener's three cases followed a peculiar granulomatous rhinitis. Lindsay's case apparently first manifested itself as a painless depression of the bridge of the nose about a year before death due to polyarteritis nodosa. Also, one case of polyarteritis nodosa of the series reported by Davson, Ball, and Platt (1948), and that of Olesen and Myschetzky (1949), both had had a Caldwell-Luc operation performed for chronic nasal discharge and maxillary sinusitis some months before death from polyarteritis nodosa. We observed an example of this remarkable association, and the following is an account of the clinical picture, post-mortem findings, and some aspects of the pathogenesis.

\section{Case Report}

G. D., a married man aged 23, was seen on March 24, 1949, in the outpatient department of the Royal Ear, Nose, and Throat Hospital, London, complaining of increasing nasal obstruction for two months and nasal discharge for three months. The nasal 
mucosa was intensely congested and granular, with a great deal of crusting in the vestibule. Radiographs showed opacity of both antra and a cloudy left frontal sinus. On April 7, 1949, the patient was seen again and a biopsy taken from the mucosa of the right inferior turbinate. This showed (Fig. 1) " fragments of granulation tissue with foreign body giant cells and eosinophils and some areas of necrosis. No evidence of malignant change." He was not seen again until April 27, 1949, when he was transferred from another hospital, where he had been admitted in the meantime, with a note stating that he had been treated with sulphadiazine and his condition had not improved.

On examination the patient was seen to be an ill-looking man with gingivitis, a large perforation in the cartilaginous septum, and crusting in both sides of his nose. Inspection of the ears showed injection of both drums posteriorly and oedema of the arytenoid region of the larynx. A right Caldwell-Luc operation was performed, and a portion of the antral mucosa removed for histological examination.

The patient had persistent slight fever after operation. On May 17 oedema of both lower lids was observed. On May 23 the patient was rather drowsy, vomiting greenish material, and had a very foul postnasal discharge. Oliguria was present. He passed two ounces of urine in which were blood and albumin on May 24. The blood pressure was $155 / 80 \mathrm{~mm}$. Hg. On May 28 oedema of the ankles was increasing, and the patient was very drowsy. His nose was still full of crusts, and he passed little urine. His blood pressure was $170 / 80 \mathrm{~mm}$. $\mathrm{Hg}$, and on May 30 it was $170 / 90$ $\mathrm{mm}$. $\mathrm{Hg}$.

The patient was treated with

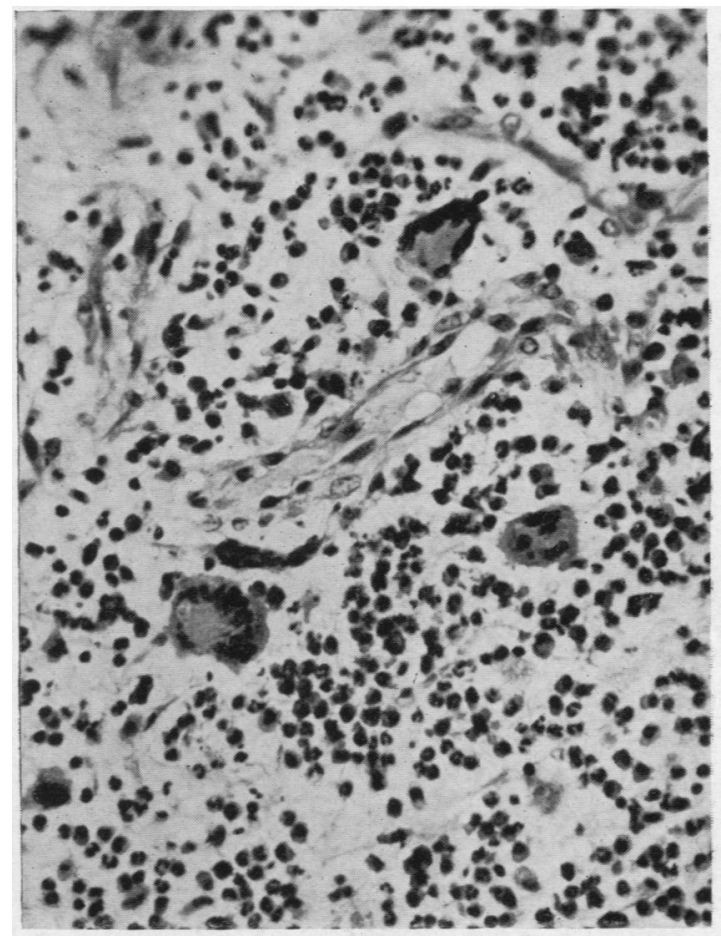

Fig. 1.-Photomicrograph of right inferior turbinate showing numerous giant cells and eosinophils. (Haematoxylin and eosin. $\times$ 285.) penicillin from April 29 to May 9, and from May 17 to May 30. The total amount given was 16,000,000 units. From May 21 "albucid" (sulphacetamide) was given four-hourly. Death took place on June 4, 1949.

\section{Laboratory Data}

Examination of biopsy material from the antrum (Dr. Lucas) showed no normal mucosa. It was replaced partly by granulation tissue and partly by fibrous tissue with some areas of haemorrhage and pus. Giant cells were numerous, especially in the granulation tissue. There was no evidence of specific inflammation or neoplastic change.

Bacteriological Findings. - Culture from the maxillary antrum (29.4.49) showed a mixed growth of Streptococcus beta haemolyticus (penicillin-sensitive) and Staphylococcus 
pyogenes (penicillin-sensitive). On 23.5.49 Staphylococcus pyogenes (penicillin-resistant and streptomycin-sensitive) only was grown.

Blood culture (25.5.49) was sterile after seven days' incubation.

Blood Counts. - (30.4.49) White blood cells, 7,650; haemoglobin, 70\% (Sahli) ; red blood. cells, 3,300,000; polymorphs, $73.5 \%$; lymphocytes, $23.5 \%$; monocytes, $3 \%$; eosinophils, not seen. On 24.5 .49 white blood cells, 8,800; haemoglobin, $72 \%$; red blood cells, 4,570,000. On 31.5.49 white blood cells, 31,800; and on 3.6.49 white blood cells, 27,300 .

The Wassermann reaction was negative.

Urine (27.5.49).-Albumin present. Numerous red blood cells and granular casts seen in deposit. Culture sterile.

Blood Urea. - On 24.5.49 was $160 \mathrm{mg}$ \% , and thereafter (28.5.49) $220 \mathrm{mg}$. \% ; (31.5.49) $260 \mathrm{mg} . \%$; (3.6.49) $320 \mathrm{mg}$ \%.

Cerebrospinal Fluid.-On 26.5.49 C.S.F. was clear. Pressure, $130 \mathrm{~mm}$. ; cells, 3 ; proteins, $10 \mathrm{mg}$. \% ; chlorides, $731 \mathrm{mg} . \%$.

\section{Necropsy Findings}

Necropsy was performed six hours after death.

The body was that of a well-built, well-nourished, pale young man. There was some dry purulent discharge from the nose, and pitting oedema of both legs.

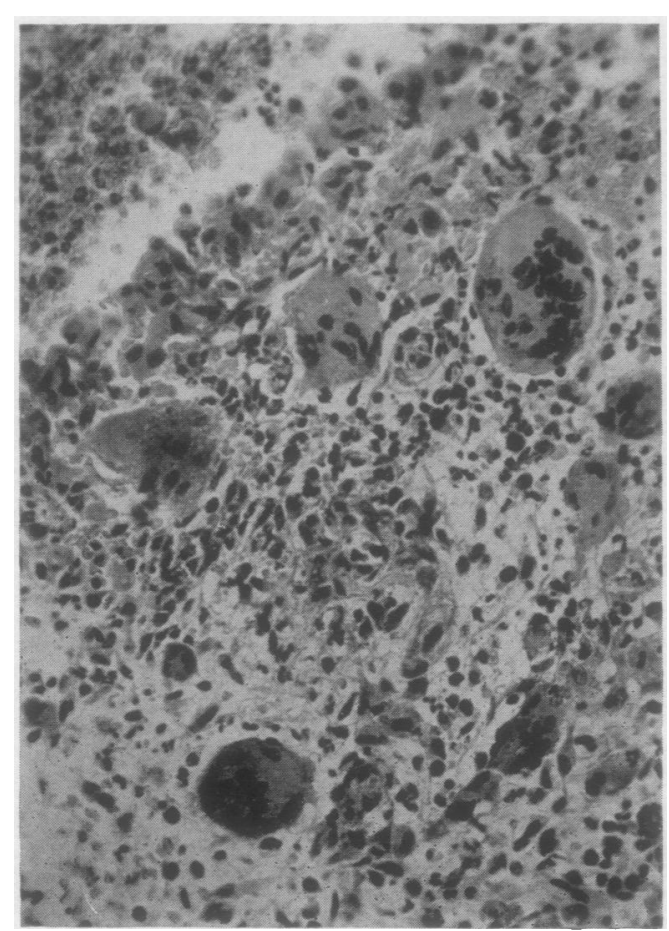

FIG. 2.-Photomicrograph of maxillary antrum showing granulation tissue with numerous multinucleated giant cells of the foreign-body type. (Haematoxylin and eosin. $\times 240$.)
Skull.-Maxillary sinuses contained a great deal of purulent exudate. Ethmoids and frontal sinuses filled with thick creamy yellow purulent exudate. Middle ear was dry; the meninges dry and smooth. Brain, normal apart from pallor. Blood vessels normal.

Chest.-There were numerous shallow ulcers in the larynx and trachea, the largest about $2 \mathrm{~cm}$. in diameter, of "mousebitten" appearance with irregular edges and necrotic bases, in the subglottic area.

About $200 \mathrm{ml}$. of clear fluid occupied each pleural cavity. Patchy, dark red, haemorrhagic consolidation in lower lobes of both lungs. On pressure great amounts of sanious fluid escaped from the cut surface. Frothy fluid in air passages. Some emphysema of upper lobes. The heart was normal apart from cloudy swelling.

Abdomen. - The peritoneal cavity contained about 4 pints of clear, strawcoloured fluid. The firm, lobular pattern of the liver was accentuated. The spleen (about $400 \mathrm{~g}$.) was soft, and the cut surfaces revealed a hyperplastic pulp and prominent Malpighian bodies. 
The kidneys were enlarged (about 250 g.). The capsule stripped easily, revealing smooth swollen surfaces peppered with numerous petechial haemorrhages. On section the glomeruli were very prominent and the cortex similarly contained petechiae. No infarcts were present.

The pelves, ureter, bladder, and prostate were normal, as also were the alimentary canal, thyroid, and adrenals.

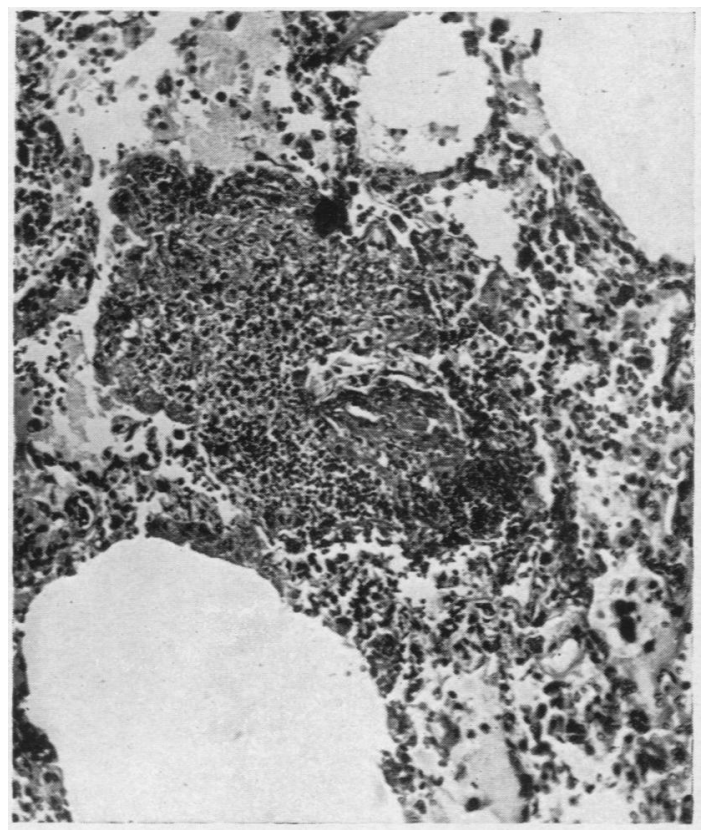

FIG. 3.-Photomicrograph of emphysematous lung tissue showing necrotizing arteriole surrounded by pleomorphic inflammatory cells. (Haematoxylin and eosin. $\times$ 130.)

F I G . 4 - M'a rked fibrinoid necrosis of follicular arteriole in the spleen surrounded by a predominant ly leucocytic exudate. (Haematoxylin and eosin. $\times 75$.)
Microscopical Examination. Sections were stained with haematoxylin and eosin, van Gieson, phosphotungstic acid-haematoxylin, Weigert's elastic stain, Gram, and Ziehl-Neelsen.

Sections from the maxillary antrum (Fig. 2) showed non-specific, highly vascular granulation tissue, containing numerous multinucleated giant cells of the foreign-body type often with bizarre arrangements of the nuclei and a foamy cytoplasm. There were numerous areas of necrosis infiltrated by polymorphonuclear leucocytes, and extensive haemorrhage in some areas. Some vessels appeared to be involved in the necrotic process, but it was not possible to assess the type of vascular lesion in this necrotic granulation tissue. Gram and Ziehl-Neelsen stains showed no organisms.

Sections of the purulent tissue from the frontal sinus showed mainly

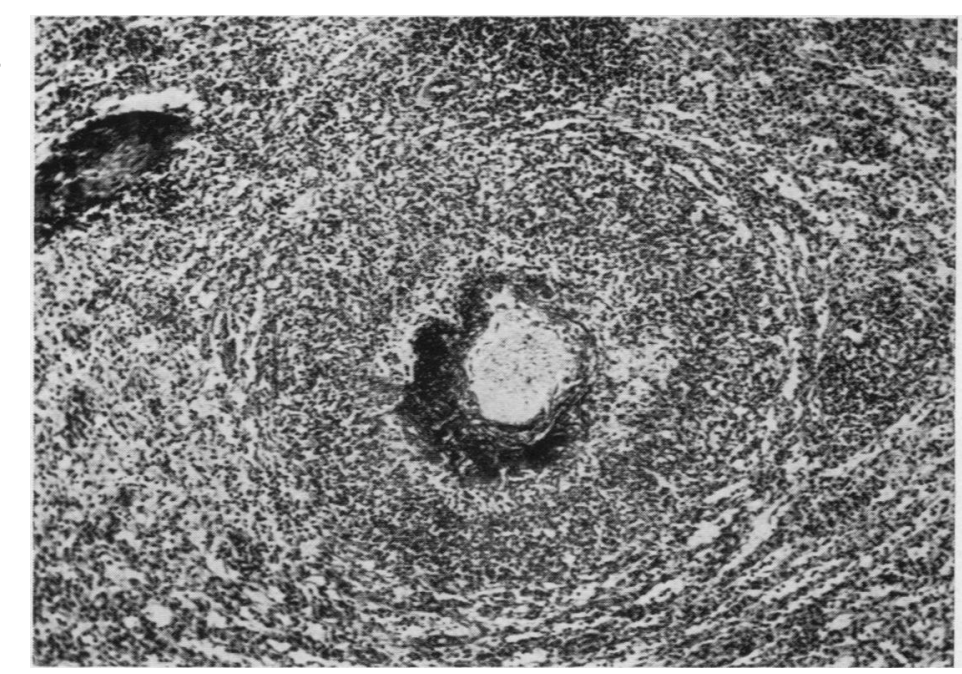




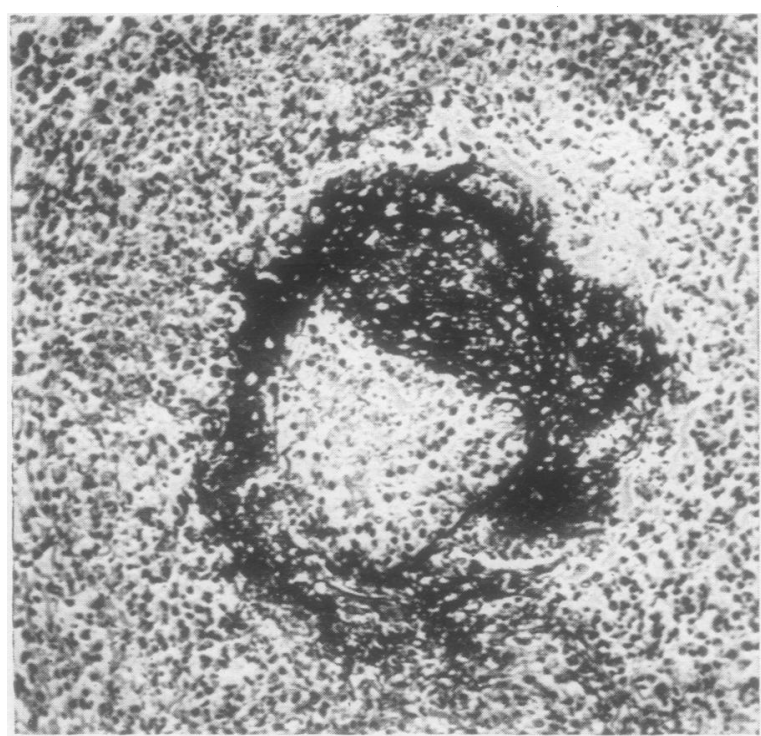

Fig. 5.-Fibrinoid necrosis of follicular arteriole in the spleen. (Phosphotungstic acid-haematoxylin. $\times 160$.) necrotic purulent exudate with a few large mononuclear cells.

The floor and edges of the large ulcer from the subglottic area were formed by a necrotizing granulation tissue consisting of numerous leucocytes, epithelioid cells, and a fair number of giant cells. There was some resemblance to a tuberculous ulcer, but no tubercle bacilli were found either in section or in cultures.

Lungs. - Sections from the lower lobe of the lungs showed widespread haemorrhage and collateral emphysema. In the emphysematous area there were vascular changes suggestive of polyarteritis nodosa (Fig. 3). The small necrotic arterioles were surrounded by a zone of polymorphs, lymphocytes, and a few eosinophils.

Spleen.-Sections of the spleen showed a very widespread lesion affecting particularly the follicular arterioles (Fig. 4) and small arteries and possibly damaging the veins as well. The fully developed lesions consisted of segmental or total fibrinoid necrosis of the

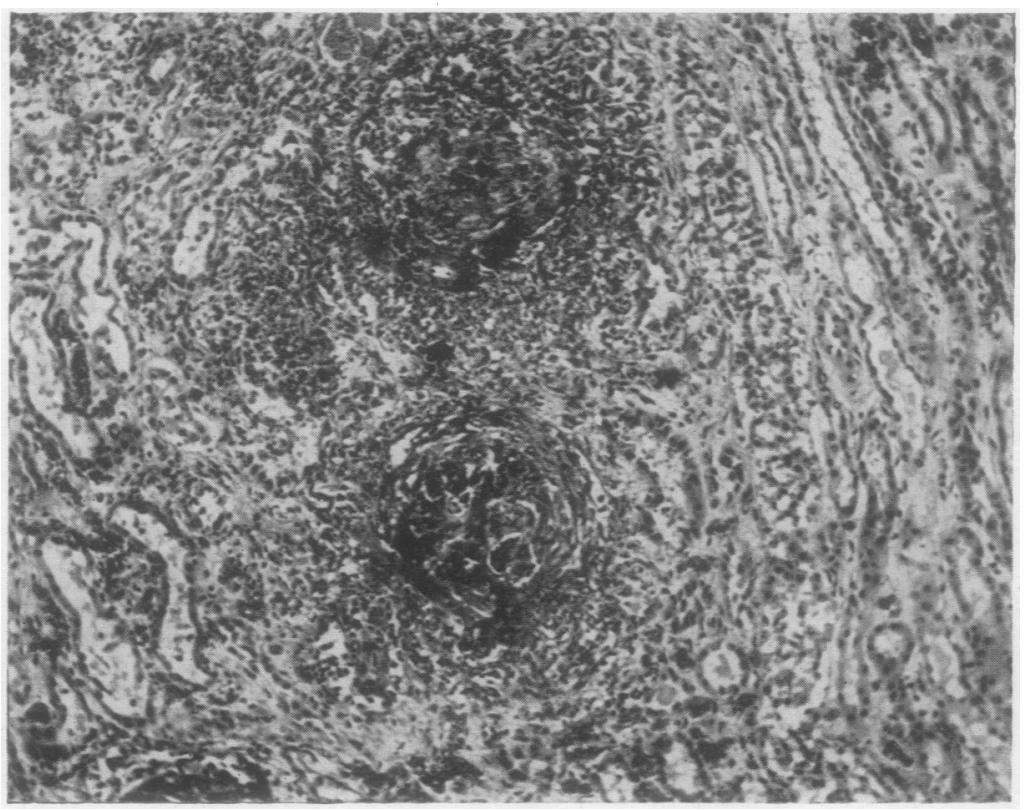

Fig.6.-Necrotic glomeruli of the kidney with periglomerular infiltration, the parenchymatous elements separated by a young granulation tissue. (Haematoxylin and eosin. $\times$ 95.) 
walls, well shown in sections stained with phosphotungstic acid-haematoxylin (Fig. 5). There was pleomorphic cellular exudation around the vessels, polymorphonuclear leucocytes predominating. The hyperplastic pulp contained numerous plasma cells, eosinophil and neutrophil leucocytes, and focal aggregations of leucocytes, some of which surrounded the trabeculae ("Trabeculitis" of More, McMillan, and Duff, 1946). The eosinophilic necrotic material of the vascular lesions seemed in places to be extending into the surrounding exudate.

Kidneys.-There was widespread damage throughout the cortex of the kidneys, and all the glomeruli were apparently affected (Fig. 6). In places some of the glomerular loops showed hyaline and fibrinoid necrosis and elsewhere all the loops were affected. The fibrinoid material formed thrombi, and in some glomeruli almost filled the capsular space (Fig. 7). There was marked proliferation of the epithelial cells of Bowman's capsule with epithelial crescent formation in many glomeruli. Some glomeruli were completely disorganized and replaced by granulation tissue, in which it was difficult to trace the remnants of the glomerular tufts. There was marked periglomerulitis, especially around some enlarged and distended glomeruli, which were surrounded by a wide zone of radially arranged cellular exudate, consisting of polymorphs, histiocytes, fibroblasts, and a moderate number of eosinophil leucocytes (Fig. 8). The parenchymatous elements of the cortex and medulla were separated by a young granulation tissue containing numerous eosinophils. Many of the tubules were dilated and contained cellular and granular casts. The majority of the afferent and other arterioles showed partial or total hy:aline or fibrinoid necrosis. Only a round homogeneous ball- or ring-like structure of necrotic material remained in place of some arterioles which were surrounded by a radially arranged zone of neutrophil and eosinophil leucocytes and histiocytes (Fig. 9). The intralobar and arcuate arteries showed no necrosis, but in some instances there was perivascular infiltration with lymphocytes. An arcuate vein showed localized necrosis with associated leucocyte infiltration.

The liver showed some congestion and a few vascular lesions. A few branches of the portal vein were necrotic and surrounded by lymphocytes, monocytes, and numerous eosinophils.

The myocardium showed some fibrosis and a few small foci of mononuclear cells in the perivascular tissue. There was no endocarditis.

The carotid arteries and jugular veins showed no change.

The thyroid, tonsils, and submaxillary gland showed no change. The base of the tongue, however, showed a few necrotic vessels surrounded by granulomatous nodules among the mucous glands.

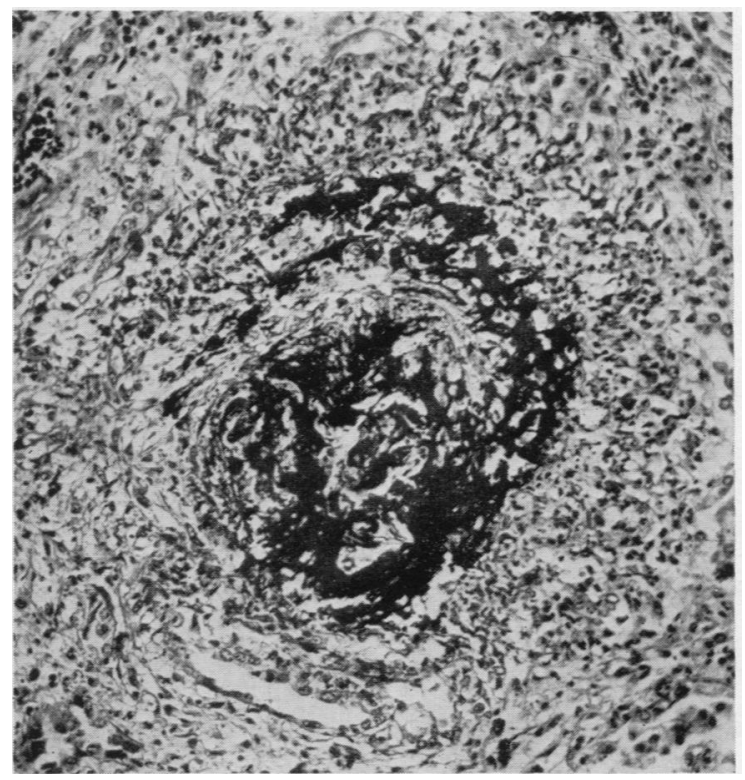

FIG. 7.- Extensive fibrinoid necrosis of glomerulus of the kidney. (Phosphotungstic acid-haematoxylin. $\times 145$.) 


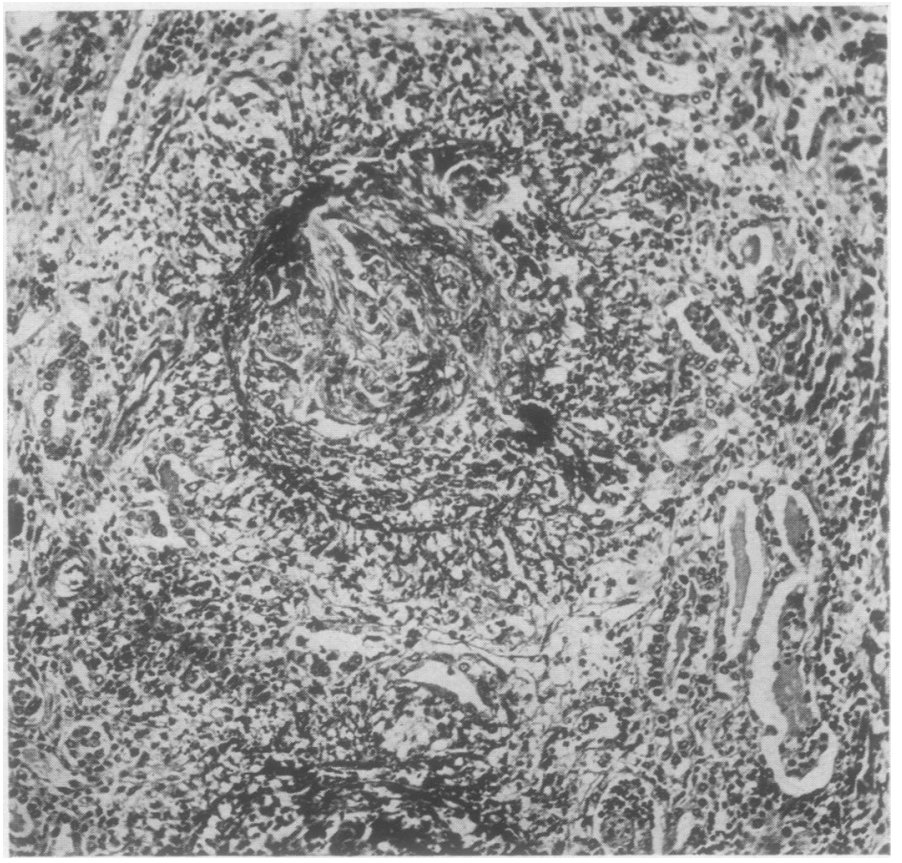

\section{Discussion}

The case described presents the remarkable association of two types of lesions: (1) giant cell granulomata of the upper respiratory tract, and (2) widespread necrotizing vascular lesions resembling polyarteritis nodosa.

The condition of the nose and of the paranasal sinuses, the first apparent site of a giant-cellular granulomatous reaction encountered in some cases of polyarteritis, dominated the clinical picture in the beginning. This initial stage of chronic sinusitis, lasting about four to five months, was followed, as in other cases, by fatal renal failure and uraemia.

The kidneys showed the microscopic features of the rapidly progressive type I of nephritis (Ellis,
FIG. 8.-Disorganized distended glomerulus of the kidney with epithelial proliferation surrounded by a radially arranged zone of inflammatory cells. (Haematoxylin and eosin. $\times$ 120.)

FIG. 9.-Total fibrinoid necrosis of arteriole of kidney surrounded by exudate with numerous eosinophils. (Haematoxylin and eosin. $X$ 235.)

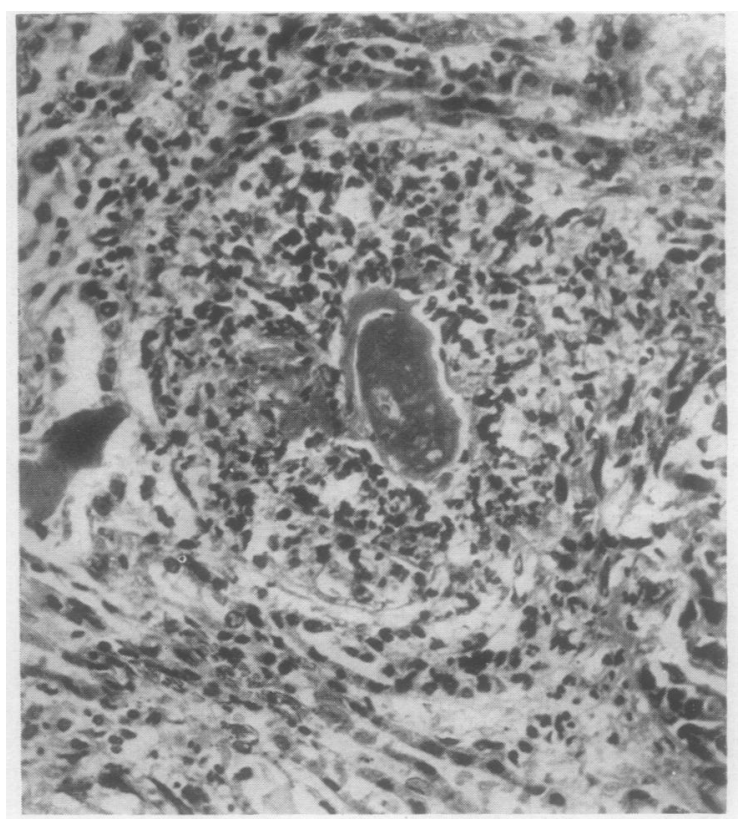


1942), namely, explosive lesions of the glomeruli, definite periglomerular inflammatory reaction, and inflammatory infiltration of the interstitial tissue. There was marked hyaline and fibrinoid necrosis of the glomerular tufts and arterioles.

There was also widespread necrotizing angiitis in other viscera, especially in the spleen and the lungs, but also in the liver.

The extra-renal vascular changes suggested polyarteritis nodosa, and the renal lesions were also consistent with the description of the kidney in the microscopic form of polyarteritis nodosa (Davson, Ball, and Platt, 1948 ; Davson and Platt, 1949). In a case like this it is, however, very difficult to draw an absolute distinction between the rapidly progressive type I of nephritis and polyarteritis nodosa (Group I of Davson et al., 1948). In any case the renal and vascular lesions certainly are connected and two distinct pathogenetic factors may be considered: (1) Hypertension due to nephritis causing in turn the necrotizing vascular lesions ; (2) hypersensitivity as the underlying cause of both the renal and vascular changes primarily affecting the vascular system.

There is evidence (Smith and Zeek ; Zeek, Smith, and Weeter, 1948) to support the hypothesis that polyarteritis nodosa is associated with sharply rising hypertension and is not so much the result of hypersensitivity to known or unknown antigens. Numerous authors, however, believe that polyarteritis nodosa is a manifestation of the anaphylactic type of hypersensitivity (Rich, 1942a, 1942b ; Rich and Gregory, 1943).

In our case the blood pressure was never very high and only rose to $170 / 90 \mathrm{~mm}$. $\mathrm{Hg}$ shortly before death from renal failure and uraemia. On the other hand there was a certain amount of morphological evidence that the lesion was of the kind described by Zeek et al. (1948) as "hypersensitivity angiitis," and attributed by them to hypersensitivity. These authors described a vascular lesion as "hypersensitivity angiitis" in seven cases of necrotizing arteritis in men which showed clinical evidence of hypersensitivity during life, usually to one of the sulphonamides. In distinction to the "classical" type of polyarteritis nodosa in men and rats, hypersensitivity angiitis affected only the small arterioles, in particular the follicular arterioles in the spleen. The lungs and liver were also affected. There was no evidence of healing and frequently the entire wall of the small vessels presented fibrinoid necrosis. There was also necrotizing glomerulitis characterized mainly by exudation and necrosis, with little evidence of the epithelial proliferation so marked in the kidneys of the case described.

The aetiology of the condition also remains obscure. Weinberg (1946) points to the history of antecedent chronic infection and bacterial hypersensitivity.

The organisms grown in our case during illness and from post-mortem specimens, namely Staphylococcus pyogenes and Streptococcus beta haemolyticus, are both capable of producing necrotizing glomerulitis and necrotizing vascular lesions.

In any case of polyarteritis nodosa complicating a disease the drug or drugs used should also be considered as causative agents (Pulvertaft, 1949). Our patient had been treated with sulphadiazine, sulphacetamide ("albucid"), and penicillin.

Hypersensitivity to sulphonamides, especially to sulphathiazole, has been incriminated in the causation of necrotizing vascular lesions resembling polyarteritis nodosa 
(Hagemann and Blake, 1937 ; Erskine, 1939 ; French and Weller, 1942 ; Lederer and Rosenblatt, 1942 ; Merkel and Crawford, 1942 ; Rich, 1942a, 1942b ; Lichtenstein and Fox, 1946 ; van Rijssel and Meyler, 1948 ; Olesen and Myschetzky, 1949 ; and others).

Duff et al. (1946) studied a series of 375 necropsies in which it was known that considerable doses of sulphonamides had been given during life. In 22 cases lesions attributable to the sulphonamide treatment were found, the most frequent lesion being a granulomatous reaction encountered in 13 out of the 22 cases. In seven cases an acute necrotizing arteritis was found whilst four out of 22 cases had both lesions. These authors believe that the granulomata belong to, and are part of, the vascular disease, and Lindsay et al. (1944) suggest that polyarteritis nodosa be considered in any granulomatous lesion of unknown aetiology.

In our case we assume that the giant-cell granulomata had been present for three to five months and histologically confirmed in the maxillary antrum about 10 weeks before death. It would thus appear that the granulomata were the first manifestation of the vascular disease possibly due to hypersensitivity to an unknown agent.

\section{Summary}

A case is described of giant-cell granulomata of unknown aetiology in the paranasal sinuses associated with necrotizing vascular lesions resembling polyarteritis nodosa terminating in renal failure.

The vascular lesions were widespread, affecting the arterioles of the viscera, including the kidneys and the spleen, and presented the morphological features of "hypersensitivity angiitis" as described by Zeek et al. (1948).

Evidence is presented that the paranasal sinuses or the nose can be the first site of the peculiar granulomatous reaction encountered in some cases of polyarteritis nodosa.

Our thanks are due to Dr. Lucas for his interest and helpful encouragement; to Mr. E. S. Bird, F.I.M.L.T., for the sections ; and to Mr. E. V. Willmott, F.R.P.S., for the photomicrographs.

\section{REFERENCES}

Banowitch, M. M., Polayes, S. H., and Charet, R. (1942). Ann. intern. Med., 16, 1149.

Davson, J., Ball, J., and Platt, R. (1948). Quart. J. Med. n.s., 17, 175.

and Platt, R. (1949). Ibid., 18, 149.

Duff, G. L., More, R. H., and McMillan, G. C. (1946). Amer. J. Path., 22, 646.

Ellis, A. (1942). Lancet, $1,72$.

Erskine, D. (1939). Brit. J. vener. Dis., 15, 260.

French, A. J., and Weller, C. V. (1942). Amer. J. Path., 18, 109.

Hageman, P. O., and Blake, F. G. (1937). J. Amer. med. Ass., 109, 642.

Klinger, H. (1931). Frankfurt. $Z$. Path., 42, 455.

Lederer, M., and Rosenblatt, P. (1942). J. Amer. med. Ass., 119, 8.

Lichtenstein, L., and Fox, L. J. (1946). Amer. J. Path., 22, 665.

Lindsay, S., Aggeler, P. M., and Lucia, S. P. (1944). Ibid., 20, 1057.

Merkel, W. C., and Crawford, R. C. (1942). J. Amer. med. Ass., 119, 770.

More, R. H., McMillan, G. C., and Duff, G. L. (1946). Amer. J. Path., 22, 703.

Neumann, R. (1940). Arch. Path. Anat., 306, 389.

Olesen, H., and Myschetzky, A. (1949). Acta path. microbiol. scand., 26, 142.

Pulvertaft, R. J. (1949). Proc. R. Soc. Med., 42, 502. 
Rich, A. R. (1942a). Bull. Johns Hopk. Hosp., 71, 123. (1942b). Ibid., 71, 375. and Gregory, J. E. (1943). Ibid., 72, 65.

Rijssel, T. G. van, and Meyler, L. (1948). Acta med. scand., 132, 251.

Rössle, R. (1936-7). Arch. Ohr.-Nas.-, u. Kehlk-Heilk., 142, 193.

Smith, C. C., and Zeek, P. M. (1947). Amer. J. Path., 23, 147.

Smith, J. F. (1948). J. Path. Bact., 60, 489.

Wegener, F. (1939). Beitr. path. Anat., 102, 36.

Weinberg, T. (1946). Amer. J. clin. Path., 16, 784.

Zeek, P. M., Smith, C. C., and Weeter, J. C. (1948). Amer. J. Path., 24, 889. 